\title{
The Impact of Post-Synthetic Linker Functionalization of MOFs on Methane Storage: The Role of Defects
}

\author{
Petra Ágota Szilágyi ${ }^{*}$, Pablo Serra-Crespo², Jorge Gascon ${ }^{3}$, Hans Geerlings ${ }^{3,4}$ and \\ Bernard Dam ${ }^{3}$ \\ 'Department of Pharmaceutical, Chemical and Environmental Sciences, University of Greenwich, Chatham, UK, \\ ${ }^{2}$ Department of Radiation Science and Technology, Delft University of Technology, Delft, Netherlands, ${ }^{3}$ Department of \\ Chemical Engineering, Delft University of Technology, Delft, Netherlands, ${ }^{4}$ Shell Technology Centre, Amsterdam, Netherlands
}

OPEN ACCESS

Edited by: Nicholas P. Stadie, ETH Zürich, Switzerland

Reviewed by: Nicolaas Vermeulen, Northwestern University, USA Michael Fischer, University of Bremen, Germany Nicholas M. Musyoka, Council for Scientific and Industrial Research (CSIR), South Africa

*Correspondence: Petra Ágota Szilágyi p.a.szilagyi@greenwich.ac.uk

Specialty section:

This article was submitted to Hydrogen Storage and Production,

a section of the journal Frontiers in Energy Research

Received: 29 January 2016 Accepted: 08 March 2016 Published: 29 March 2016

Citation:

Szilágyi PÁ, Serra-Crespo $P$, Gascon J, Geerlings H and Dam B (2016) The Impact of Post-Synthetic

Linker Functionalization of MOFs on Methane Storage: The Role of Defects.

Front. Energy Res. 4:9. doi: 10.3389/fenrg.2016.00009
Natural gas is increasingly being viewed as one of the most viable alternatives to gasoline. However, its vehicular application will only be widespread if safe and high-capacity methane stores are developed. In this work, we report an over 33\% increase in methane uptake on a post-synthetically modified metal-organic framework. The underlying mechanism for this dramatic increase is due to lattice defects formed upon post-synthetic modification. This method may open new approaches to natural gas storage.

Keywords: defects, metal-organic frameworks, methane storage, post-synthetic modification, dangling linker

\section{INTRODUCTION}

Natural gas or methane is a viable alternative to gasoline, owing to its competitive cost, purity, and existing distribution infrastructure. In addition, it is environmentally less harmful than gasoline; while the combustion of methane results in the generation of $0.89 \mathrm{MJ}$ per mole $\mathrm{CO}_{2}$ emitted, the combustion of gasoline only produces $0.63 \mathrm{MJ}$ per mole $\mathrm{CO}_{2}$, resulting in some $30 \%$ lower carbon emissions. Despite its appealing properties, methane displays a number of drawbacks for vehicular applications, such as its low density, apolarity, and the fact that it forms an explosive mixture with air. For its application as an energy carrier, particularly for vehicular transport, it therefore needs to be (i) safely stored and (ii) densified to obtain a competitive volumetric energy density. The current technology for on-board application makes use of compressed methane at room temperature and $c a$. 250 bar. Such high pressures raise safety issues and result in higher costs, poorer volume effectiveness, and a limited driving range. Liquefied natural gas is an alternative allowing for longer driving range, but it still raises concerns associated with safety hazards and costs (Yeh, 2007). On the other hand, adsorbed natural gas may be safe and cost-effective if a low-cost high-capacity adsorbent is developed. Particularly, the Advanced Research projects Agency-Energy of the US Department of Energy set a target that 315 volumes of methane at standard pressure and temperature should be adsorbed by 1 volume of adsorbent at max 65 bar pressure and at ambient temperature. Metalorganic frameworks (MOFs) (Kitagawa et al., 2004; Rowsell and Yaghi, 2004) have been highlighted as promising materials for methane storage owing to their high surface areas, adequate pore volumes, as well as chemical and topological tunability (Getman et al., 2012; Peng et al., 2013). However, owing to the weak interaction of methane molecules with the framework, to increase methane capacities, it is essential that both the surface area and the framework-methane interaction strength are increased. 
It has been reported that lattice defects of MOFs may alter their uptake of $\mathrm{CO}_{2}$ and $\mathrm{H}_{2}$ (Yang et al., 2012; Bueken et al., 2014; Ren et al., 2015). It is very likely that this phenomenon will have an impact on methane storage too. In particular, coordinatively unsaturated metal sites (Chen et al., 2011; Getman et al., 2012; Peng et al., 2013; Seung Koh et al., 2015) and pore diameters (Matranga et al., 1992; Cracknell et al., 1993; Gándara et al., 2014) have been highlighted to determine MOF methane capacities. Lattice defects would influence both of these by cation vacancies and linker defects. In this work, we demonstrate that lattice defects may be introduced into the MIL-101 (Férey et al., 2005) framework using solvent-assisted linker exchange (SALE) and measure its impact on methane uptake.

\section{MATERIALS AND METHODS}

MIL-101(Cr) was synthesized, hydrothermally, according to Férey's method (Férey et al., 2005). Synthesis of $\mathrm{NH}_{2}$-MIL-101(Cr) was carried out by the chemical reduction of $\mathrm{NO}_{2}-\mathrm{MIL}-101(\mathrm{Cr})$, as described by Stock using a longer reaction time $(16 \mathrm{~h})$ (Bernt et al., 2011; Juan-Alcañiz et al., 2013). SALE was carried out by infusing an aqueous solution of 2-amino-1,4-benzendicarboxylic acid $\left(\mathrm{NH}_{2}-\mathrm{BDC}\right)$ into MIL-101(Cr), described in Szilágyi et al. (2014). UV-vis spectra were measured with a Perkin-Elmer Lambda 900 spectrophotometer equipped with an integrating sphere ("Labsphere") in the 200-800 nm range. DRIFTS spectra were acquired of the samples pretreated at $453 \mathrm{~K}$ in a $20 \mathrm{~cm}^{3} \mathrm{~min}^{-1}$. The flow, on a Nicolet model 8700 spectrometer, equipped with a high-temperature cell, and a DTGS-TEC detector, with 256 scans at $4 \mathrm{~cm}^{-1}$ resolution from 4000 to $500 \mathrm{~cm}^{-1}$ and using $\mathrm{KBr}$ as reference. Thermal analysis was carried out on samples pretreated under air flow at $323 \mathrm{~K}$ under air flow of $60 \mathrm{~cm}^{3} \mathrm{~min}^{-1}$ at a temperature ramp rate of $5 \mathrm{~K} \mathrm{~min}^{-1}$ in the $323-1073 \mathrm{~K}$ range, using a TGA/SDTA851e instrument by Mettler Toledo. Methane uptake was determined at $273 \mathrm{~K}$ by volumetric technique using a BEL Japan (Belsorp HP) apparatus. Isotherms were measured on typically $0.2 \mathrm{~g}$ sample. Before every measurement, the adsorbent was pretreated by increasing the temperature to $473 \mathrm{~K}$ at a rate of $10 \mathrm{~K} \mathrm{~min}^{-1}$ under vacuum and maintaining the temperature overnight.

\section{RESULTS AND DISCUSSION}

In materials science, it is generally acknowledged that point, line, surface, and volume defects have tremendous impact on the properties of condensed matter. As MOFs are a relatively new type of material, their defect structures and types are largely unknown (Cheetham et al., 2016). In fact, MOFs were practically viewed as ideal crystalline solids, and gas adsorption has been discussed in terms of fairly rigid and perfectly ordered crystal lattices (Simon et al., 2015; Smit, 2015). Most defects reported are related to the heterogeneity of building blocks, such as mixed cationic units (Brozek and Dincă, 2013; Szilágyi et al., 2013) or linkers (Deng et al., 2010; Karagiaridi et al., 2012; Szilágyi et al., 2014). It has, however, recently emerged that, similar to other materials classes, MOFs display a range of lattice defects (Fang et al., 2015), such as vacancies (Vermoortele et al., 2012a;
Wu et al., 2013), surface defects (Choi et al., 2008; Ameloot et al., 2013), dislocations (Shöâeè et al., 2008; Walker and Slater, 2008), and defect voids (Whittington et al., 2014). More importantly, the physical and chemical impact of MOF defects has begun to be recognized (Bueken et al., 2014; Cliffe et al., 2014; Fang et al., 2014; Whittington et al., 2014; Ren et al., 2015).

There are various ways of introducing lattice defects into a MOF, among which post-synthetic (PS) linker exchange is prominent (Vermoortele et al., 2012b; Shearer et al., 2014; Tu et al., 2014). SALE should thus be an ideal tool to introduce defects in a MOF. MIL-101(Cr) has been chosen as the material under scrutiny, as it has been demonstrated that its linkers may be exchanged post-synthetically (Szilágyi et al., 2014); it will thus allow the verification of (i) the engineering of defect sites through SALE and (ii) its impact on methane adsorption. It has been reported that $-\mathrm{NH}_{2}$ groups (Wood et al., 2012), and in general $\mathrm{N}$ sites (Li et al., 2015), may enhance methane storage on porous materials. To take advantage of this improvement, the PS exchange of the BDC linker to its $\mathrm{NH}_{2}$-BDC has been chosen and SALE exchange was carried out, resulting in the post-synthetically linkerexchanged sample, PSM (Szilágyi et al., 2014). Furthermore, in order to distinguish between the effect of functional groups and that of defects the pristine $\mathrm{NH}_{2}$-MIL-101 was also synthesized.

Defects may be categorized as external or internal defects, where the former ones only occur on particle surfaces. Internal surface defects may be static or dynamic (Cairns and Goodwin, 2013). Dynamic effects, $c f$., ligand rotation, will be disregarded as they are not formed upon or affected by SALE. Furthermore, synchrotron X-ray diffraction patterns and BET surface areas (MIL-101: $2136 \mathrm{~m}^{2} \mathrm{~g}^{-1}, \mathrm{NH}_{2}$-MIL-101: $2001 \mathrm{~m}^{2} \mathrm{~g}^{-1}$, and PSM: $2059 \mathrm{~m}^{2} \mathrm{~g}^{-1}$ ) (Szilágyi et al., 2014) reveal an identical crystallographic structure in these samples, highlighting the lack of volume defects. As $\mathrm{N}_{2}, \mathrm{H}_{2}$, and $\mathrm{CH}_{4}$ molecules are of similar size and polarity, surface and line defects on MOFs should affect their adsorption similarly. It has been previously shown that this is not the case for the hydrogen and nitrogen uptake of SALE-treated MIL-101 (Szilágyi et al., 2014), which suggests that potential surface and line defects do not play a key role in these systems. Therefore, only point defects will be further discussed. Three types of point defects may occur in MOFs, such as metal node vacancy, linker vacancy, and linker dislocation. Metal node vacancy may only occur upon SALE if it is accompanied by linker defects as the linker-metal bonds need to be first broken for the metal to be able to leach out. Linker vacancy and linker dislocation (dangling) are depicted in Figures 1A-C.

In order to verify the effect of MOF defects on methane adsorption, it first has to be established whether they have been introduced in framework. UV-vis spectroscopy gives information on metal-linker bonds, which could be affected by linker vacancies or dislocations. The metal-ligand charge-transfer peak undergoes a shift to higher wavelengths upon the addition of amino ligands (Supplementary Material), similar to what was observed for UiO-66 (Hendrickx et al., 2015). This shift appears to be proportional to the amino substitution as the peak maximum is at $514 \mathrm{~nm}$ for the pristine MIL-101, $528 \mathrm{~nm}$ for the pure $\mathrm{NH}_{2}$-MIL-101, and $518 \mathrm{~nm}$ for PSM, containing ca. $20 \% \mathrm{NH}_{2}-$ BDC (Szilágyi et al., 2014). It cannot thus be directly attributed to 

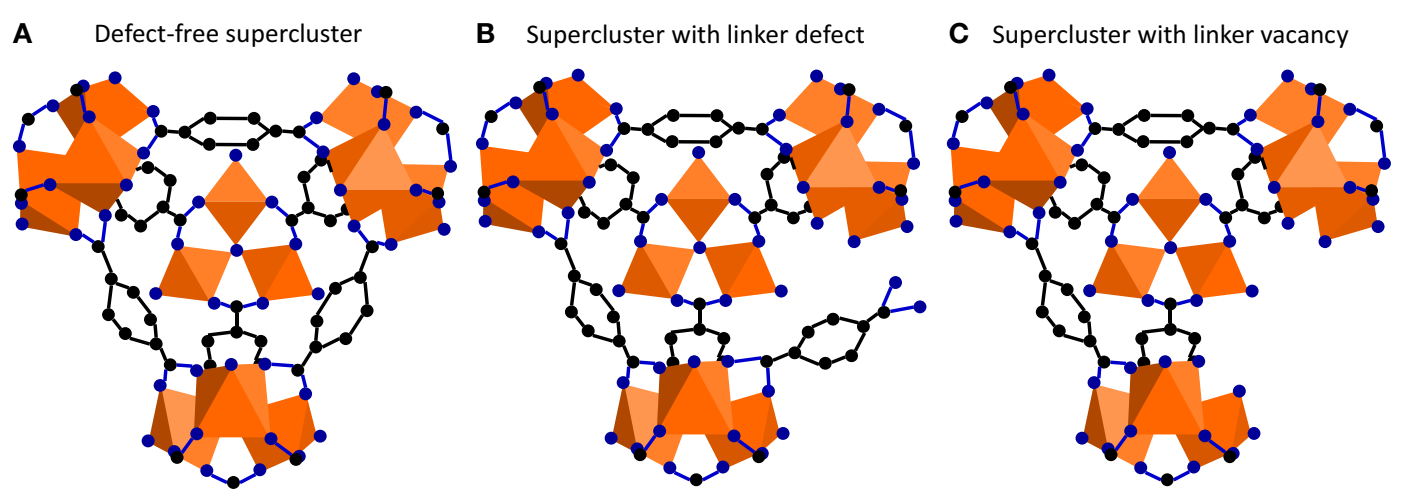

FIGURE 1 | MIL-101 supercluster (A) defect-free, (B) with dangling linker, and (C) with linker vacancy; the orange polyhedra represent the cationic units, whereas $\mathrm{C}$ and $\mathrm{O}$ atoms are depicted in black and blue, respectively.
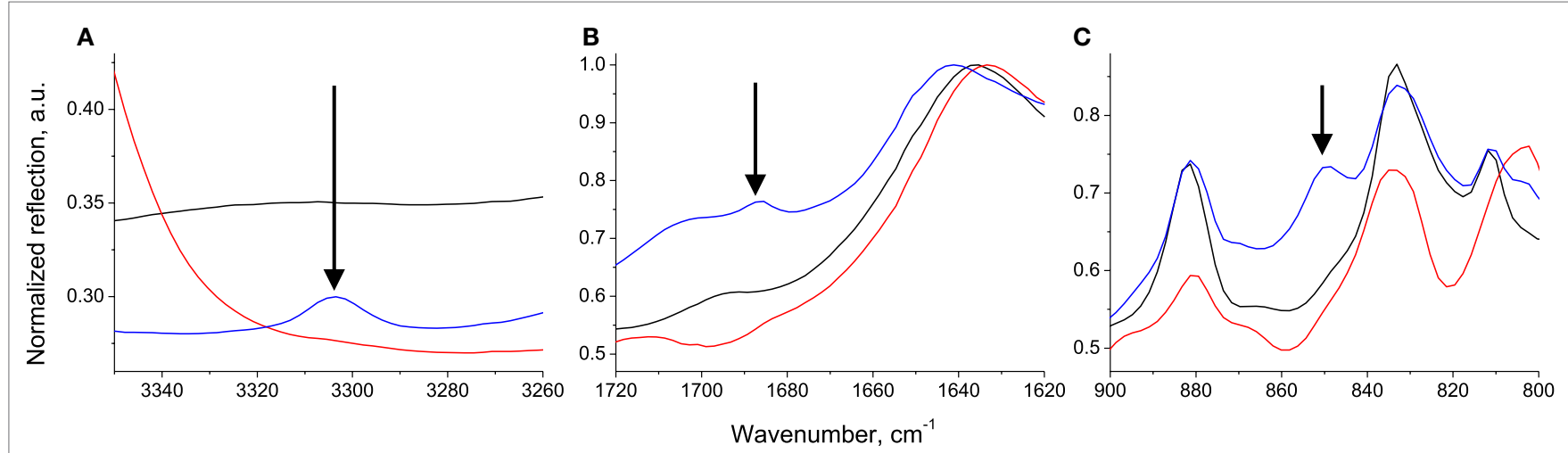

FIGURE 2 | DRIFTS spectra of MIL-101 (black), $\mathrm{NH}_{2}-\mathrm{MIL}-101$ (red), and PSM (blue) in the (A) O-H stretching, (B) C=O stretching, and (C) C-H bending regions.

defects. Infrared spectroscopy, on the other hand, reveals some vibrational modes only present in the PSM sample (Figure 2). In the IR spectrum of PSM, an $\mathrm{O}-\mathrm{H}$ stretching mode belonging to a carboxylate appears at $3301 \mathrm{~cm}^{-1}$, a free $\mathrm{C}=\mathrm{O}$ stretching mode appears at $1685 \mathrm{~cm}^{-1}$ [which is a value very close to what was calculated for the $\mathrm{NH}_{2}$ - $\mathrm{BDC}$ (Karabacak et al., 2010)] and a $\mathrm{CH}$ out-of-plane deformation mode appears at $848 \mathrm{~cm}^{-1}$. These additional modes only occur in the post-synthetically modified sample, which suggests that defects have been introduced in the pristine MIL-101 upon SALE. Furthermore, as only two types of linker defects could be introduced - either linker vacancy or linker dislocation - it can be deduced that the defects formed are dangling linkers. The additional $-\mathrm{OH}$ and $\mathrm{C}=\mathrm{O}$ stretching modes reveal the presence of uncoordinated carboxylate groups. Correspondingly, the coordination sphere of the $\mathrm{Cr}^{3+}$ in the cationic units should be saturated with $\mathrm{H}_{2} \mathrm{O}$, as observed in the appearance of additional $\mathrm{Cr}-\mathrm{O}$ stretching modes for the PSM sample (Figure 2). In addition, from previous PXRD and BET results, it had been deduced that this cannot be due to unreacted linkers (Szilágyi et al., 2014). Finally, our thermal gravimetric analysis (TGA) highlights that there is no substantial difference in the linker content of PSM and the pristine MIL-101 (Figure 3).
The presence of dangling linker defects has been also confirmed by TGA as an additional decomposition step at around $430^{\circ} \mathrm{C}$ can be observed for the PSM sample (Figure 3). This step corresponds well with what was previously observed in the literature for the loss of carboxylate groups (Gadipelli and Guo, 2014). It is possible that the formation of the linker-cationic unit bond upon MOF self-assembly differs greatly from that upon linker exchange, and it is mechanistically hindered and/or energetically unfavorable for the linkers to bridge two cationic units post-synthetically, whence the presence of dangling linkers.

As displayed in Figure 1B, dangling linker defects alter the topology of potential methane adsorption pockets. To probe this, methane adsorption isotherms were measured, and a number of methane molecules adsorbed per formula unit $\left(\mathrm{Cr}_{3}(\mathrm{OH})\right.$ $\left.\mathrm{O}[\text { linker }]_{3}\right)$ and volumetric adsorption $\left(\mathrm{cm}^{3} \mathrm{CH}_{4}\right.$ STP $\mathrm{cm}^{-3}$ sample) were compared for the three samples for the practically relevant pressure values of 5, 35, and 65 bar (Table 1).

For hydrogen adsorption, it was shown that the amino functional group acts as an adsorption site and indeed from the UV-vis spectra one expects that it will have an effect on the methane adsorption (Szilágyi et al., 2014). The addition of amino groups in the pristine MIL-101 increases the absorbed photon wavelength for both the pure $\mathrm{NH}_{2}$-MIL-101 and PSM samples 


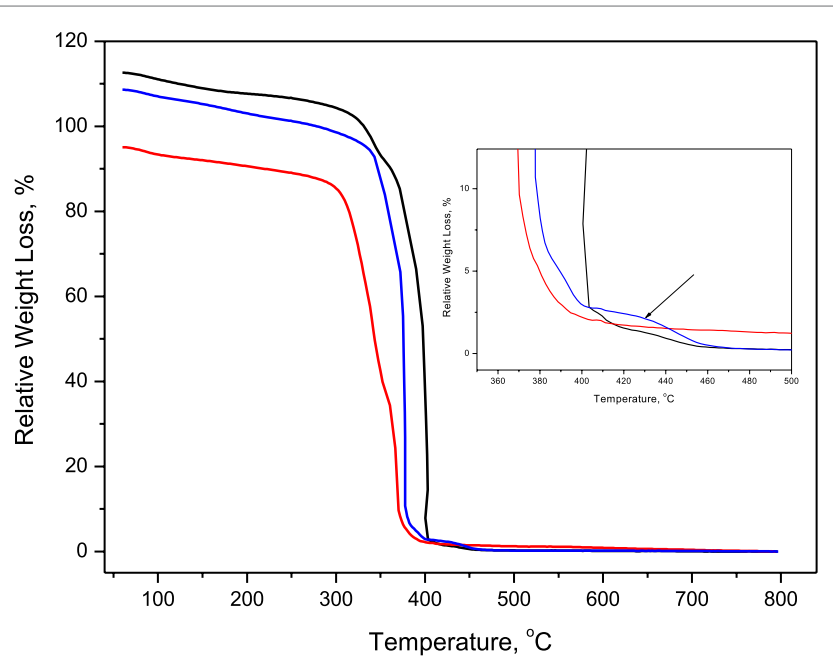

FIGURE 3 | Normalized TGA curves for MIL-101 (black), $\mathrm{NH}_{2}-\mathrm{MIL}-101$ (red), and PSM (blue), highlighting the additional decomposition step at ca. $430^{\circ} \mathbf{C}$ in the insert. One hundred percent of relative weight loss corresponds to the perfectly pure, crystalline, and completely dehydrated $\mathrm{MOF} \rightarrow \mathrm{Cr}_{2} \mathrm{O}_{3}$ reaction, normalized to the molar mass of the samples. The first degradation step of the functionalized MOFs occurs at lower temperatures than that of the pristine MIL-101, which corresponds to the breaking off of the $-\mathrm{NH}_{2}$ functional group.

TABLE 1 | Adsorbed $\mathrm{CH}_{4}$ at 5, 35, and 65 bar.

\begin{tabular}{llrrr}
\hline Sample/pressure & $\mathbf{5}$ bar & $\mathbf{3 5}$ bar & $\mathbf{6 5}$ bar \\
\hline MIL-101(Cr) & Molecules/formula unit & 1.2 & 4.3 & 5.2 \\
& $\mathrm{~cm}^{3} / \mathrm{cm}^{3}$ & 25.5 & 89.5 & 108.9 \\
$\mathrm{NH} \mathrm{N}_{2}-\mathrm{MIL}-101(\mathrm{Cr})$ & Molecules/formula unit $^{3}$ & 1.4 & 4.1 & 5.0 \\
& $\mathrm{~cm}^{3} / \mathrm{cm}^{3}$ & 26.6 & 84.1 & 101.0 \\
$\mathrm{PSM}$ & $\mathrm{Molecules/formula} \mathrm{unit}^{3}$ & 1.6 & 5.7 & 7.1 \\
& $\mathrm{~cm}^{3} / \mathrm{cm}^{3}$ & 33.1 & 118.9 & 150.5 \\
\hline
\end{tabular}

(Supplementary Material), which corresponds to a lower photon energy absorbed, i.e., a smaller band gap (Hendrickx et al., 2015). A smaller band gap in turn is indicative of weaker bonding (Ouyang et al., 2009). In this case, the $\mathrm{Cr}-\mathrm{O}$ bonds are less strong, which should modify the interaction strength of methane on the cationic unit. By comparing the number of adsorbed $\mathrm{CH}_{4}$ molecules per formula unit on MIL-101 and $\mathrm{NH}_{2}$-MIL-101, it is clear that more methane molecules are adsorbed on the functionalized MOF in the low-loading region. This is related to the adsorption of the stronger sites, such as the coordinatively unsaturated metal site (Dietzel et al., 2009). However, at higher loading, or higher pressures, corresponding to pore filling, this effect no longer plays a key role. Therefore, it is possible to separate the effect of linker functionalization from that of linker defects at higher loadings.

Most importantly, the PSM sample has higher methane uptake than both pure MOFs, MIL-101 and $\mathrm{NH}_{2}$-MIL-101, both gravimetrically (Figure 4) and per formula unit throughout the studied pressure range, including the practically relevant 5-35 bar. Furthermore, it should be noted that the said increase is reproducible and is of similar magnitude, by one-third throughout the isotherm.

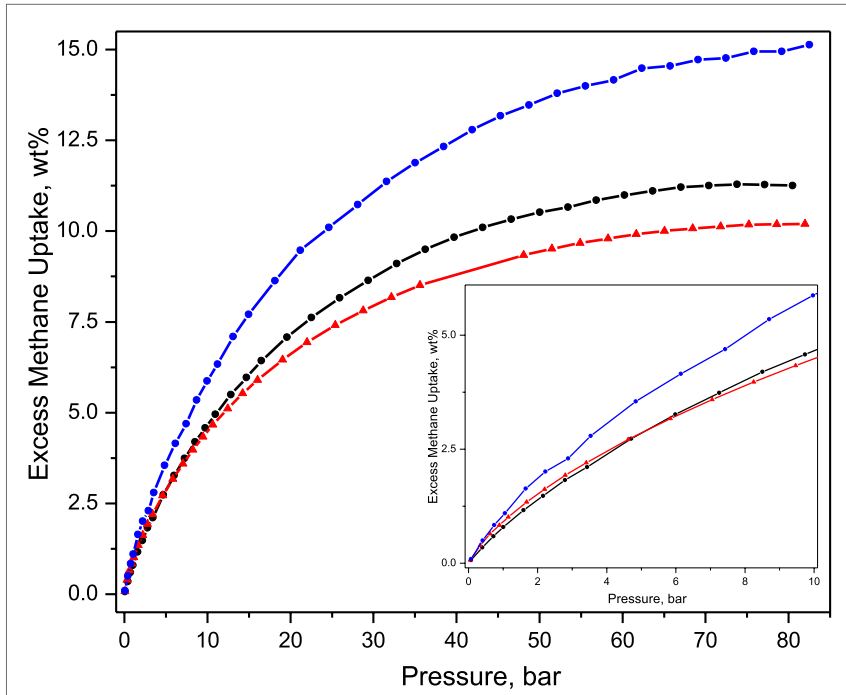

FIGURE 4 | Excess methane uptake on MIL-101 (black), $\mathrm{NH}_{2}-\mathrm{MIL-101}$ (red), and PSM (blue); isotherm at low methane loading in insert.

It has to be emphasized that the presence of new amino adsorption sites would only affect the methane uptake at the low-loading region, up to 5 bar, this is in good agreement with what was observed for the pure $\mathrm{NH}_{2}$-MIL-101. In addition, the extent of the observed increase of methane adsorption on PSM in the lowloading range surpasses that observed for the pure $\mathrm{NH}_{2}-\mathrm{MIL}-101$, which has a higher proportion of amino groups, highlighting that additional effects need to be taken into consideration to explain the enhanced methane capacity of the post-synthetically modified MIL-101(Cr). In general, this enhancement cannot be explained by increased surface area as (i) MIL-101 $\left(2136 \mathrm{~m}^{2} \mathrm{~g}^{-1}\right)$ has a higher surface area than PSM $\left(2059 \mathrm{~m}^{2} \mathrm{~g}^{-1}\right)$ (Szilágyi et al., 2014) and (ii) the increase is observed throughout the isotherm and not just at high loadings, where the surface area or pore filling would play a key role.

These considerations lead to the explanation that the increase is a consequence of the defects introduced, i.e., dangling linkers upon SALE. It is stipulated that the dislocated linkers opened new pockets of adsorption, increasing the methane uptake throughout the isotherm. Such adsorption enhancement corresponds to a larger number of various, already existing, adsorption sites, or to an increased surface area available for the adsorption of methane. By analyzing the different pores and clusters in the MIL-101 structure, it may be possible that the superclusters become available for the/more $\mathrm{CH}_{4}$ molecules. The diameter of the superclusters is $6 \AA$ (Shin et al., 2015), so it is not able to accommodate two methane molecules (kinetic diameter of $3.8 \AA$ ) in its closed form. The opening of supercluster would increase its effective volume, approaching the ideal $7.5 \AA$ value that has been observed for HKUST-1 (Rowsell and Yaghi, 2006). It should be noted that this is in agreement with our previous findings on the hydrogen uptake in these systems that did not seem to be influenced on the high loading (low interaction strength) regime by PSM or defects as the kinetic diameter of $\mathrm{H}_{2}$ is $2.9 \AA$, and thus the opening of the supercluster will not 
effectively increase the number of $\mathrm{H}_{2}$ molecules contained within (Szilágyi et al., 2014). We would like to point out that the observed $\mathrm{CH}_{4}$ uptake for MIL-101(Cr) is lower than what was published previously (Hamon et al., 2009), this is also underpinned by a higher than $100 \%$ relative weight loss upon thermal treatment (Figure 3), which may be indicative of either metal vacancies or impurities whose decomposition results in the formation of volatile products. In the case of the pristine MIL-101 and PSM samples, it is likely to be a consequence of the latter one, which is also supported by the observed surface area being smaller than published elsewhere (Kim et al., 2013). On the other hand, lower than $100 \%$ relative weight loss is indicative of either linker vacancies or the presence of impurities, resulting in non-volatile thermal decomposition products. The lower than $100 \%$ relative weight loss observed for $\mathrm{NH}_{2}-\mathrm{MIL}-101$ is a consequence of some residual reagent applied in its synthesis (Bernt et al., 2011; Juan-Alcañiz et al., 2013).

\section{CONCLUSION}

We showed that it is possible to introduce defects in the robust MIL-101 with SALE. Although the formation of various types of defects may be possible, they are overwhelmingly dangling

\section{REFERENCES}

Ameloot, R., Vermoortele, F., Hofkens, J., De Schryver, F. C., De Vos, D. E., and Roeffaers, M. B. J. (2013). Three-dimensional visualization of defects formed during the synthesis of metal-organic frameworks: a fluorescence microscopy study. Angew. Chem. 125, 419-423. doi:10.1002/ange.201205627

Bernt, S., Guillerm, V., Serre, C., and Stock, N. (2011). Direct covalent post-synthetic chemical modification of Cr-MIL-101 using nitrating acid. Chem. Commun. 47, 2838-2840. doi:10.1039/c0cc04526h

Brozek, C. K., and Dincă, M. (2013). Ti3+-, V2+/3+-, Cr2+/3+-, Mn2+-, and Fe2+-substituted MOF-5 and redox reactivity in Cr- and Fe-MOF-5. J. Am. Chem. Soc. 135, 12886-12891. doi:10.1021/ja4064475

Bueken, B., Reinsch, H., Reimer, N., Stassen, I., Vermoortele, F., Ameloot, R., et al. (2014). A zirconium squarate metal-organic framework with modulator-dependent molecular sieving properties. Chem. Commun. 50, 10055-10058. doi:10.1039/C4CC03764B

Cairns, A. B., and Goodwin, A. L. (2013). Structural disorder in molecular framework materials. Chem. Soc. Rev. 42, 4881-4893. doi:10.1039/c3cs35524a

Cheetham, T., Bennett, T. D., Coudert, F.-X., and Goodwin, A. (2016). Defects and disorder in metal organic frameworks. Dalton Trans. 45, 4113-4126. doi:10.1039/C5DT04392A

Chen, L., Grajciar, L., Nachtigall, P., and Düren, T. (2011). Accurate prediction of methane adsorption in a metal-organic framework with unsaturated metal sites by direct implementation of an ab initio derived potential energy surface in GCMC simulation. J. Phys. Chem. C 115, 23074-23080. doi:10.1021/jp2090878

Choi, J.-S., Son, W.-J., Kim, J., and Ahn, W.-S. (2008). Metal-organic framework MOF-5 prepared by microwave heating: factors to be considered. Microporous Mesoporous Mater. 116, 727-731. doi:10.1016/j.micromeso.2008.04.033

Cliffe, M. J., Wan, W., Zou, X., Chater, P. A., Kleppe, A. K., Tucker, M. G., et al. (2014). Correlated defect nanoregions in a metal-organic framework. Nat. Commun. 5, 4176. doi:10.1038/ncomms5176

Cracknell, R. F., Gordon, P., and Gubbins, K. E. (1993). Influence of pore geometry on the design of microporous materials for methane storage. J. Phys. Chem. 97, 494-499. doi:10.1021/j100104a036

Deng, H., Doonan, C. J., Furukawa, H., Ferreira, R. B., Towne, J., Knobler, C. B., et al. (2010). Multiple functional groups of varying ratios in metal-organic frameworks. Science 327, 846-850. doi:10.1126/science.1181761

Dietzel, P. D. C., Besikiotis, V., and Blom, R. (2009). Application of metalorganic frameworks with coordinatively unsaturated metal sites in storage and linkers, which allow the adsorption of an increased amount of $\mathrm{CH}_{4}$ molecules on the framework. Given the high proportion of increased adsorption, over $33 \%$, we are confident that the ultimate methane capacity of better performing MOFs could be significantly increased, and these result may open new possibilities in adsorbed natural gas technologies.

\section{AUTHOR CONTRIBUTIONS}

Dr. PAS carried out the syntheses, IR and UV-vis measurements, Dr. PS-C measured the methane adsorption isotherms and carried out the thermal gravimetric analysis. All authors contributed to discussions and the interpretation of the experimental data.

\section{FUNDING}

The authors would like to acknowledge financial support by the Agentschap.nl (\#EOSLT07052).

\section{SUPPLEMENTARY MATERIAL}

The Supplementary Material for this article can be found online at http://journal.frontiersin.org/article/10.3389/fenrg.2016.00009

separation of methane and carbon dioxide. J. Mater. Chem. 19, 7362-7370. doi:10.1039/b911242a

Fang, Z., Bueken, B., De Vos, D. E., and Fischer, R. A. (2015). Defect-engineered metal-organic frameworks. Angew. Chem. Int. Ed. 54, 7234-7254. doi:10.1002/ anie. 201411540

Fang, Z., Dürholt, J. P., Kauer, M., Zhang, W., Lochenie, C., Jee, B., et al. (2014). Structural complexity in metal-organic frameworks: simultaneous modification of open metal sites and hierarchical porosity by systematic doping with defective linkers. J. Am. Chem. Soc. 136, 9627-9636. doi:10.1021/ja503218j

Férey, G., Mellot-Draznieks, D., Serre, C., Millange, F., Dutour, J., Surblé, S., et al. (2005). A chromium terephthalate-based solid with unusually large pore volumes and surface area. Science 309, 2040-2042. doi:10.1126/science.1116275

Gadipelli, S., and Guo, Z. (2014). Postsynthesis annealing of MOF-5 remarkably enhances the framework structural stability and $\mathrm{CO}_{2}$ uptake. Chem. Mater. 26, 6333-6338. doi:10.1021/cm502399q

Gándara, F., Furukawa, H., Lee, S., and Yaghi, O. M. (2014). High methane storage capacity in aluminum metal-organic frameworks. J. Am. Chem. Soc. 136, 5271-5274. doi:10.1021/ja501606h

Getman, R. B., Bae, Y.-S., Wilmer, C. E., and Snurr, R. Q. (2012). Review and analysis of molecular simulations of methane, hydrogen, and acetylene storage in metal-organic frameworks. Chem. Rev. 112, 703-723. doi:10.1021/cr200217c

Hamon, L., Serre, C., Devic, T., Loiseau, T., Millange, F., Férey, G., et al. (2009). Comparative study of hydrogen sulfide adsorption in the MIL-53(Al, Cr, Fe), MIL-47(V), MIL-100(Cr), and MIL-101(Cr) metal-organic frameworks at room temperature. J. Am. Chem. Soc. 131, 8775-8777. doi:10.1021/ja901587t

Hendrickx, K., Vanpoucke, D. E. P., Leus, K., Lejaeghere, K., Van Yperen-De Deyne, A., Van Speybroeck, V., et al. (2015). Understanding intrinsic light absorption properties of UiO-66 frameworks: a combined theoretical and experimental study. Inorg. Chem. 54, 10701-10710. doi:10.1021/acs.inorgchem.5b01593

Juan-Alcañiz, J., Ferrando-Soria, J., Luz-Minguez, I., Serra-Crespo, P., Skupien, E., Santos, V. P., et al. (2013). The oxamate route, a versatile post-functionalization for metal incorporation in MIL-101(Cr): catalytic applications of $\mathrm{Cu}, \mathrm{Pd}$, and Au. J. Catal. 307, 295-304. doi:10.1016/j.jcat.2013.08.001

Karabacak, M., Cinar, M., Unal, Z., and Kurt, M. (2010). FT-IR, UV spectroscopic and DFT quantum chemical study on the molecular conformation, vibrational and electronic transitions of 2-aminoterephthalic acid. J. Mol. Struct. 982, 22-27. doi:10.1016/j.molstruc.2010.07.033

Karagiaridi, O., Lalonde, M. B., Bury, W., Sarjeant, A. A., Farha, O. K., and Hupp, J. T. (2012). Opening ZIF-8: a catalytically active zeolitic imidazolate 
framework of sodalite topology with unsubstituted linkers. J. Am. Chem. Soc. 134, 18790-18796. doi:10.1021/ja308786r

Kim, J., Lee, Y.-R., and Ahn, W. S. (2013). Dry-gel conversion synthesis of Cr-MIL-101 aided by grinding: high surface area and high yield synthesis with minimum purification. Chem. Commun. 49, 7647-7649. doi:10.1039/ c3cc 44559 c

Kitagawa, S., Kitaura, R., and Noro, S. (2004). Functional porous coordination polymers. Angew. Chem. Int. Ed. 43, 2334-2375. doi:10.1002/anie.200300610

Li, B., Wen, H.-M., Wang, H., Wu, H., Yildirim, T., Zhou, W., et al. (2015). Porous metal-organic frameworks with Lewis basic nitrogen sites for high-capacity methane storage. Energy Environ. Sci. 8, 2504-2511. doi:10.1039/C5EE01531F

Matranga, K. R., Stella, A., Myers, A. L., and Glandt, E. D. (1992). Molecular simulation of adsorbed natural gas. Sep. Sci. Technol. 27, 1825-1836. doi:10.1080/01496399208019452

Ouyang, G., Sun, C. Q., and Zhu, W. G. (2009). Atomistic origin and pressure dependence of band gap variation in semiconductor nanocrystals. J. Phys. Chem. C 113, 9516-9519. doi:10.1021/jp9035309

Peng, Y., Krungleviciute, V., Eryazici, I., Hupp, J. T., Farha, O. K., and Yildirim, T. (2013). Methane storage in metal-organic frameworks: current records, surprise findings, and challenges. J. Am. Chem. Soc. 135, 11887-11894. doi:10.1021/ ja4045289

Ren, J., Langmi, H. W., Musyoka, N. M., Mathe, M., Kang, X., and Liao, S. (2015). Tuning defects to facilitate hydrogen storage in core-shell MIL-101 (Cr)@ UiO-66 (Zr) nanocrystals. Mater. Today 2, 3964-3972. doi:10.1016/j. matpr.2015.08.026

Rowsell, J. L. C., and Yaghi, O. M. (2004). Metal-organic frameworks: a new class of porous materials. Microporous Mesoporous Mater. 73, 3-14. doi:10.1016/j. micromeso.2004.03.034

Rowsell, J. L. C., and Yaghi, O. M. (2006). Effects of functionalization, catenation, and variation of the metal oxide and organic linking units on the low-pressure hydrogen adsorption properties of metal-organic frameworks. J. Am. Chem. Soc. 128, 1304-1315. doi:10.1021/ja056639q

Seung Koh, H., Kumar Rana, M., Wong-Foy, A. G., and Siegel, D. J. (2015). Predicting methane storage in open-metal-site metal-organic frameworks. J. Phys. Chem. C 119, 13451-13458. doi:10.1021/acs.jpcc.5b02768

Shearer, G. C., Chavan, S., Ethiraj, J., Vitillo, J. G., Svelle, S., Olsbye, U., et al. (2014). Tuned to perfection: ironing out the defects in metal-organic framework UiO66. Chem. Mater. 26, 4068-4071. doi:10.1021/cm501859p

Shin, J. W., Kim, M., Cirera, J., Chen, S., Halder, G. J., Yersak, T. A., et al. (2015). MIL-101(Fe) as a lithium-ion battery electrode material: a relaxation and intercalation mechanism during lithium insertion. J. Mater. Chem. A 3, 4738-4744. doi:10.1039/C4TA06694D

Shöâeè, M., Agger, J. R., Anderson, M. W., and Attfield, M. P. (2008). Crystal form, defects and growth of the metal organic framework HKUST-1 revealed by atomic force microscopy. CrystEngComm 10, 646-648. doi:10.1039/b718890k

Simon, C. M., Kim, J., Gomez-Gualdron, D. A., Camp, J. S., Chung, Y. G., Martin, R. L., et al. (2015). The materials genome in action: identifying the performance limits for methane storage. Energy Environ. Sci. 8, 1190-1199. doi:10.1039/ C4EE03515A

Smit, B. (2015). Screening materials relevant for energy technologies. Chimia 5, 248-252. doi:10.2533/chimia.2015.248

Szilágyi, P. Á, Serra-Crespo, P., Dugulan, I., Gascon, J., Geerlings, H., and Dam, B. (2013). Post-synthetic cation exchange in the robust metal-organic framework MIL-101(Cr). CrystEngComm 15, 10175-10178. doi:10.1039/ c3ce42006j

Szilágyi, P. Á, Weinrauch, I., Juan-Alcañiz, J., Serra-Crespo, P., Grzech, A., Oh, H., et al. (2014). Interplay of linker functionalization and hydrogen adsorption in the metal-organic framework MIL-101. J. Phys. Chem. C 118, 19572-19579. doi:10.1021/jp5050628

Tu, B., Pang, Q., Wu, D., Song, Y., Weng, L., and Li, Q. (2014). Ordered vacancies and their chemistry in metal-organic frameworks. J. Am. Chem. Soc. 136, 14465-14471. doi:10.1021/ja5063423

Vermoortele, F., Vandichel, M., Van de Voorde, B., Ameloot, R., Waroquier, M., Van Speybroeck, V., et al. (2012a). Electronic effects of linker substitution on lewis acid catalysis with metal-organic frameworks. Angew. Chem. Int. Ed. 51, 4887-4890. doi:10.1002/anie.201108565

Vermoortele, F., Ameloot, R., Alaerts, L., Matthessen, R., Carlier, B., Ramos Fernandez, E. V., et al. (2012b). Tuning the catalytic performance of metalorganic frameworks in fine chemistry by active site engineering. J. Mater. Chem. 22, 10313-10321. doi:10.1039/c2jm16030g

Walker, A. M., and Slater, B. (2008). Comment upon the screw dislocation structure on HKUST-1 $\{111\}$ surfaces. CrystEngComm 10, 790-791. doi:10.1039/ b802158a

Whittington, C. L., Wojtas, L., and Larsen, R. W. (2014). Ruthenium(II) tris(2,2'bipyridine)-templated $\operatorname{zinc}(\mathrm{II}) \quad$ 1,3,5-tris(4-carboxyphenyl)benzene metal organic frameworks: structural characterization and photophysical properties. Inorg. Chem. 53, 160-166. doi:10.1021/ic402614w

Wood, B. C., Bhide, S. Y., Dutta, D., Kandagal, V. S., Deep Pathak, A., Punnathanam, S. N., et al. (2012). Methane and carbon dioxide adsorption on edgefunctionalized graphene: a comparative DFT study. J. Chem. Phys. 137, 054702. doi:10.1063/1.4736568

Wu, H., Chua, Y. S., Krungleviciute, V., Tyagi, M., Chen, P., Yildirim, T., et al. (2013). Unusual and highly tunable missing-linker defects in zirconium metal-organic framework UiO-66 and their important effects on gas adsorption. J. Am. Chem. Soc. 135, 10525-10532. doi:10.1021/ja404514r

Yang, S., Lin, X., Lewis, W., Suyetin, M., Bichoutskaia, E., Parker, J. E., et al. (2012). A partially interpenetrated metal-organic framework for selective hysteretic sorption of carbon dioxide. Nat. Mater. 11, 710-716. doi:10.1038/nmat3343

Yeh, S. (2007). An empirical analysis on the adoption of alternative fuel vehicles: the case of natural gas vehicles. Energy Policy 35, 5865-5875. doi:10.1016/j. enpol.2007.06.012

Conflict of Interest Statement: The authors declare that the research was conducted in the absence of any commercial or financial relationships that could be construed as a potential conflict of interest.

The handling Editor declared a past coauthorship with the authors Petra Ágota Szilágyi and Hans Geerlings and states that the process nevertheless met the standards of a fair and objective review.

Copyright $\odot 2016$ Szilágyi, Serra-Crespo, Gascon, Geerlings and Dam. This is an open-access article distributed under the terms of the Creative Commons Attribution License (CC BY). The use, distribution or reproduction in other forums is permitted, provided the original author(s) or licensor are credited and that the original publication in this journal is cited, in accordance with accepted academic practice. No use, distribution or reproduction is permitted which does not comply with these terms. 